\title{
ARTIGO
}

do https://doi.org/10.22481/praxisedu.v16i37.6189

\section{PROFESSORES MESTRES E DOUTORES NA EDUCAÇÃO BÁSICA DO DISTRITO FEDERAL: REALIDADE, PERSPECTIVAS E DESAFIOS}

\author{
MASTERS AND DOCTORS TEACHERS IN FEDERAL DISTRICT BASIC EDUCATION: \\ REALITY, PERSPECTIVES AND CHALLENGES
}

\author{
PROFESORES MESTROS Y DOCTORES EM LA EDUCACIÓN BÁSICA DEL \\ DISTRITO FEDERAL: REALIDAD, PERSPECTIVAS Y DESAFÍOS
}

Dayse Kelly Barreiros de Oliveira

Universidade de Brasília - Brasil

\begin{abstract}
Resumo: Este estudo tem como objeto os professores da educação básica com formação stricto sensu que atuam na educação básica pública do Distrito Federal, identificando e apontando as contribuições de tal formação no trabalho docente. Adota como método o materialismo histórico dialético, que compreende que o indivíduo não pode ser analisado separado das suas condições materiais de vida. Como estratégias metodológicas se utiliza da revisão bibliográfica, questionários e entrevistas. Possui os seguintes eixos de análise: o perfil; a trajetória profissional, com enfoque no ingresso na educação básica e no curso de pós-graduação stricto sensu; as perspectivas e os desafios dessa formação. Essa opção se deve à importância de tal trajetória para a constituição do trabalho docente. Como considerações são apontadas que a formação no mestrado/doutorado apresenta três importantes elementos incidentes no trabalho docente: a emancipação; a autonomia; e o estranhamento. As percepções encontradas caminham na direção da construção de uma relação mais consciente com o trabalho e as suas finalidades sociais.
\end{abstract}

Palavras-chave: Formação de professores. Educação básica. Pós-graduação stricto sensu.

\begin{abstract}
The purpose of this study is the teachers of basic education with postgraduate stricto sensu who work in the public basic education of the Federal District, identifying and pointing out the contributions of such training in teaching work. It adopts as dialectical historical materialism, which understands that the individual can not be analyzed apart from his material conditions of life. Methodological strategies include bibliographic review, questionnaires and interviews. It has the following axes of analysis: the profile; the professional trajectory, focusing on the entry into basic education and the post-graduate course stricto sensu; the perspectives and challenges of this training. This option is due to the importance of such trajectory for the constitution of the teaching work. As considerations are pointed out that the training in the masters / doctorate presents three important elements incident in the teaching work: the emancipation; autonomy; and strangeness. The perceptions found are moving towards building a more conscious relationship with work and its social purposes.
\end{abstract}

Keywords: Teacher training. Basic Education. Posgraduate stricto sensu. 
Resumen: Este estudio tiene como objeto a los profesores de la educación básica con formación stricto sensu que actúan en la educación básica pública del Distrito Federal, identificando y apuntando las contribuciones de tal formación en el trabajo docente. Adopta como método el materialismo histórico dialéctico, que comprende que el individuo no puede ser analizado separadamente de sus condiciones materiales de vida. Como estrategias metodológicas se utiliza de la revisión bibliográfica, cuestionarios y entrevistas. Tiene los siguientes ejes de análisis: el perfil; la trayectoria profesional, con enfoque en el ingreso en la educación básica y en el curso de postgrado stricto sensu; las perspectivas y los retos de esta formación. Esta opción se debe a la importancia de tal trayectoria para la constitución del trabajo docente. Como consideraciones se apunta que la formación en el máster / doctorado presenta tres importantes elementos incidentes en el trabajo docente: la emancipación; la autonomía; y el extrañamiento. Las percepciones encontradas caminan hacia la construcción de una relación más consciente con el trabajo y sus finalidades sociales.

Palabras clave: Formación de profesores. Educación básica. Posgraduación stricto sensu.

\section{Para início de conversa}

Instituída formalmente em meados da década de 1960, a pós-graduação brasileira, sob o contexto de expansão de universidades do período desenvolvimentista, nasce para desempenhar o papel de formar especialistas, mestres e doutores e contribuir com o avanço da produção do conhecimento no campo educacional. Desde sua criação, a pós-graduação tem passado por notável expansão.

O panorama atual da pós-graduação brasileira, segundo o diagnóstico da pós-graduação brasileira divulgado pelo Centro de Gestão e Estudos Estratégicos (CGEE), em 2016, por meio da organização de pesquisa vinculada ao Ministério da Ciência, Tecnologia, Inovações e Comunicações (MCTIC). Em 2014, ano mais recente avaliado no estudo, o Brasil formou 50,2 mil mestres e 16,7 mil doutores, comparado a 10,4 mil e 2,8 mil, respectivamente, em 1996. Se forem considerados os dez últimos anos do período, o aumento do número total de titulados foi de $92 \%$.

Ao pesquisar sobre o que tem sido produzido a respeito da pós-graduação stricto sensu em educação, verifica-se que há muitos estudos sobre a formação de professores universitários e políticas públicas de pós-graduação. Pouco se encontra sobre o destino dos egressos titulados na área de educação. As produções existentes, ora fazem um panorama geral da formação stricto sensu, em caráter mais descritivo, como as produções de Velloso (2004), ora estabelecem relação entre a educação básica e a formação pós-graduada desse segmento, como nos estudo de Curado Silva (2008), Rocha (2012), Barreiros (2013), Beccari (2013), Silva (2015).

Curado Silva (2008) contribuiu para elaboração desta investigação, pois apontou que a formação stricto sensu começa a fazer parte da formação continuada do professor de educação 
básica e, portanto, instiga os programas de pós-graduação a pensarem como se dá a relação entre formação stricto sensu e docência na educação básica. De acordo com os dados levantados pela a autora apenas $1,53 \%$ de professores com mestrado e doutorado atuam na educação básica de Goiânia, comprovando assim, que a participação de professores com formação stricto sensu nesse nível de ensino ainda é muito incipiente.

O V PNPG (2005-2010) é um dos primeiros que prevê a relação entre pós-graduação e docência na educação básica. O plano atribui aos programas stricto sensu a função de qualificar professores do ensino fundamental, médio e técnico, prevendo a necessidade de propor diretrizes e programas especiais que atendam a formação continuada do professor da educação básica.

Algumas indagações levantadas nos estudos de Curado Silva (2008) identificam uma lacuna nos propósitos, estímulos, motivos e circunstâncias em que a formação na pós-graduação stricto sensu de professores da educação básica tem sido realizada. A autora revela que não há produções que contemplem ou tentem responder a essa problemática, e é exatamente por essa razão que esta pesquisa foi desenvolvida.

Além do âmbito acadêmico com o número incipiente de pesquisas, o estudo se justifica por sua novidade e por seu caráter prospectivo, bem como sua relevância social, pelo restrito conhecimento das implicações dessa formação no mestrado/doutorado para atuação na educação básica.

Ao tratar das implicações da formação na pós-graduação stricto sensu na educação básica, problema pelo qual a pesquisa se pauta, é preciso uma imersão em dois eixos de análise: a formação na pós-graduação stricto sensu e o trabalho docente na educação básica, eixos que embasaram os tópicos a seguir.

\section{Dialogando com a teoria}

Sobre a relevância da formação na pós-graduação stricto sensu e as perspectivas profissionais após a titulação, nos apoiaremos nas contribuições de Velloso (2001, 2002, 2004) que realizou diversos estudos procurando identificar e analisar as expectativas dos discentes quanto às atividades que pretendem desenvolver logo após a conclusão do mestrado e do doutorado, assim como suas aspirações no futuro mais remoto. Outras contribuições podem ser encontradas nos estudos de Spagnolo e Gunther (1986), uma das primeiras investigações sobre o destino profissional de mestres e doutores no país em meados da década de 1980, verificando 
que a maioria dos egressos buscou a pós-graduação com interesse em pesquisa, estava geralmente satisfeita com o seu trabalho e tinha uma avaliação positiva quanto à sua formação. Antes de fazer o curso, menos da metade dos mestres trabalhava em instituição de ensino superior, em geral públicas, porém depois da titulação $70 \%$ dos titulados tiveram esse destino profissional. Entre os doutores, antes de começarem curso, cerca de $60 \%$ atuavam no ensino superior, também quase sempre público, proporção que crescia para $3 / 4$ após a obtenção do título.

Segundo Velloso (2004) desde essa época alteraram-se as políticas de pós-graduação traçadas pelas agências de fomento, mudou muito o mercado de trabalho universitário e mais ainda o mercado de empregos. Com isso, será necessário buscar o sentido da pós-graduação stricto sensu para quem a procura e de que forma tem configurado suas produções. Velloso (2004) aponta que nesse contexto começam a tomar contornos em que acrescentam novos objetivos para essa formação, um deles está na profissionalização de forma mais direta, para atender a necessidade do mercado.

A partir dos estudos de Warde (1990) as investigações no campo educacional passam a ter como tema central os estudos baseados nas experiências do cotidiano, na organização, gestão, no saber prático do professor, dentre outros, naturalizados no limite entre produzir conhecimento e manipular a prática. E ao indagar-nos sobre o tipo de conhecimento que tem sido produzido nos programas stricto sensu, dois autores trazem contribuições para a análise: Warde (1993) alertando que se atribui à pós-graduação a função de ser o foco produtor de pesquisa, mas a sua estrutura é de foco produtor de dissertações e teses. Segundo ela, há indícios de que boa parte das produções dos discentes não pode ser tomada como pesquisa, em consequência da fragilidade teórico-metodológica. Cunha (1991) já um pouco mais otimista pondera que as dissertações e teses dos programas de pós-graduação deram origem à maioria dos livros publicados, constituindo a bibliografia da educação; porém aponta que as condições de implantação e muitas vezes de funcionamento dos programas, estão baseados na lógica da improvisação.

Ainda pensando na relevância do Sistema Nacional de Pós-Graduação (SNPG), ao tratar da gênese e primeiros passos da pesquisa em educação Ferraro (2005) contribui com a exposição de três períodos: no primeiro, predominaram estudos de natureza psicopedagógica; no segundo, com predominância de estudos de natureza sociológica; e no terceiro período, predominaram os estudos de natureza econômica. Outra importante informação que o autor traz é o surgimento e importância da ANPEd que em apenas oito anos de pós-graduação já datava sua origem. A exposição de trabalhos e seleção destes representou sem dúvida, um enorme 
avanço no que se refere à disseminação da produção científica dos pesquisadores e dos programas de pós-graduação.

Revisitar a teoria nos permitiu aproximar do objeto de estudo, trazendo importantes contribuições para o mapeamento da pós-graduação brasileira. Os estudos que tiveram esse nível de ensino como objeto trouxeram informações que nos permitiram ter uma ideia geral sobre a função e a importância para o cenário educacional e atribuíram fundamental importância dessa formação para carreira docente. Para compreendermos criticamente tal relevância e por diversos trabalhos apresentarem a necessidade de reflexão sobre as políticas educacionais de formação de professores, torna-se essencial uma aproximação das diretrizes e planejamentos políticos para essa formação.

Atenta para o fato de que a formação docente atualmente é objeto de atenção da CAPES e que cabe ao SNPG organizar e avançar nas discussões e debates sobre os caminhos necessários para alcançar melhorias na Educação Básica. O PNPG em vigência, também reconhece que é necessário traçar perfil dos professores da educação básica, compreender o que motiva e o que desmotiva o trabalho docente, refletir sobre a pouca procura por licenciatura nos vestibulares, e repensar a vida na escola e o trabalho do professor. Há também a consideração de que os cursos de pós-graduação estão capacitados para a tarefa de formar professores para educação básica, "porque estão localizados em sua maioria nas universidades, lugares estes, por excelência, voltados para a realização das formações docentes” (BRASIL, 2010, p.171). É a partir dessas intenções expostas no plano que percebemos o avanço nas políticas nacionais da pós-graduação em pensar a educação básica como um assunto estratégico para o desenvolvimento social do país.

Nesse contexto, o crescimento da PG também foi refletido no campo da formação de professores do ensino básico. Segundo o Observatório do PNE, a porcentagem de funções docentes da educação básica com pós-graduação (lato sensu e stricto sensu), em 2014, alcançou a marca de 31,4\%. Em 2017, foi alcançada a marca de 36,2\% de educadores da educação básica com pós-graduação; em números absolutos, o total de 813.923. A maioria dos professores com pós-graduação possui somente a especialização. Do total de docentes, em 2017, foram 34,4\%, com especialização; $2,4 \%$, com mestrado; $0,4 \%$, com doutorado. Com base nesses dados, a soma dos percentuais excedeu o dado de $34,6 \%$, com pós-graduação, devido a existência de profissionais que possuem mais de um tipo de pós-graduação. Portanto, mesmo que seja uma parcela reduzida, é interessante pensar que os professores (que atuam na educação básica) que recorrem aos cursos de mestrado/doutorado, o fazem na tentativa de migrar para a universidade. 
Entretanto, outros buscam como investimento a formação continuada por entenderem ser parte integrante do seu processo de desenvolvimento; e o fazem, com ou sem licença, permanecendo e resistindo na educação básica. O estudo dessa realidade específica pode contribuir para as possiblidades de investimento na formação continuada de professores da educação básica enquanto política e direito de todos.

Contudo, pudemos perceber também, a partir de algumas indagações levantadas nos estudos de Curado Silva (2008), que foi identificada uma lacuna nos propósitos, estímulos, motivos e circunstâncias em que essa formação na pós-graduação stricto sensu de professores da educação básica tem sido realizada. Sua pesquisa demonstra que a tal formação começa a fazer parte da formação continuada do professor da educação básica e, portanto, instiga os programas a pensarem nas diretrizes do V e VI PNPG, que prevê a relação entre pós-graduação e docência na educação básica. A autora revela que não há produções que contemplem ou tentem responder a essa problemática, e instigada pela necessidade de preencher essa lacuna que a partir dessas colocações nasce a presente pesquisa sob o desejo de investigar sobre o trabalho docente de professores mestres e doutores e seu sentido para a educação básica.

Quando um professor de educação básica pesquisa, automaticamente cria possibilidades de beneficiar a si próprio, como a comunidade escolar, produzindo transformações na prática docente e favorecendo o desenvolvimento da pesquisa educacional pelos próprios professores da escola.

Talvez, a partir dessa aproximação seja uma oportunidade de o profissional assumir sua condição identitária a partir de reflexões como trabalhador, que cria a possibilidade de conhecimento do seu próprio eu pessoal e social, reconhecendo e colocando em prática seus conhecimentos e reflexões sistematizadas quanto à sua própria ação. Trata-se de um movimento de articulação entre teoria e prática, quando o trabalho do professor é inerentemente, imaterial e permeado de trabalho vivo. E é exatamente sobre esse trabalhador que buscou essa articulação entre teoria e prática, a partir do mestrado/doutorado, que veremos a seguir o que significou tal formação à sua profissão.

\section{Caminho metodológico}

Há de se considerar que a formação de professores e o trabalho docente não existem em si mesmos, mas são historicamente construídos, é algo que não está pronto e acabado, pois a realidade está em constante transformação. A fim de detalhar as ações realizadas no decorrer 
da pesquisa o processo metodológico se inicia pela revisão bibliográfica. A seleção dos sujeitos participantes da coleta de dados foi feita considerando a estreita relação de cada um deles com o problema da pesquisa: os movimentos pedagógicos da formação stricto sensu na educação básica. São eles: os professores mestres e doutores atuantes na docência da Secretaria de Estado de Educação do Distrito Federal (SEEDF).

Segundo dados apresentados no Censo 2018:

1. O número total de professores em sala de aula em toda rede da SEEDF, é 24.687;

2. O número total com mestrado, é 1.023;

3. O número total de professores com doutorado, é 103;

O dado indica que $4,56 \%$ dos professores da SEEDF possuem formação stricto sensu, totalizando 1.126 mestres e doutores que atuam em diferentes funções e áreas, como escolas, diretorias de ensino, sede da secretaria de educação e etc. Porém, segundo os objetivos da pesquisa realizada em 2013, de acordo com a SEEDF a quantidade de professores com formação stricto sensu que atuam na sala de aula da educação básica está representada por uma porcentagem de $73,2 \%$.

Os procedimentos para a coleta de informações e a construção do corpus deste estudo foram selecionados de acordo com os objetivos da pesquisa e são eles: a) questionário; b) entrevista. O roteiro do questionário foi composto por 29 questões, divididas em abertas e fechadas, foi pré-testado com um grupo de cinquenta e dois (52) professores, ou seja 11,60\% do total de docentes com formação stricto sensu, que atuam na educação básica do Distrito Federal. Essa porcentagem foi escolhida pelas limitações existentes referentes ao tempo disponível para a pesquisa, bem como o acesso a informação sobre a localização dos sujeitos envolvidos. Os questionários foram propostos pessoalmente e em meio eletrônico, assim que foi tomado conhecimento da lotação dos professores mestres e doutores envolvidos na pesquisa. Foram entrevistados sete (7) sujeitos, ou seja 13,46\% dos respondentes do questionário (52). O roteiro da entrevista tinha a intenção de guiar a narrativa, servindo como orientação do pesquisador e pesquisado sobre temas pertinentes ao objeto de estudo. A entrevista, se constitui de 07 questões elaboradas a fim de complementar os dados coletados pelo questionário, de forma a aprofundar a temática aproximando-se cada vez mais do objeto.

\section{Dialogando com a realidade}

Ao realizar o levantamento sobre o número de professores com formação stricto sensu trabalhando na rede de educação básica pública do GDF, conforme dados anteriormente 
expostos, ficamos surpresos com o resultado positivo. É interessante notar que parece haver um movimento dos profissionais da educação básica no sentido de buscarem ampliar sua formação por iniciativa individual. Isso ocorre pela falta de políticas de formação por parte da SEEDF, porém, é importante ressaltar, como será analisado posteriormente, que em termos de carreira a formação stricto sensu pouco acrescenta. ${ }^{1}$

Já de início os dados apontam a possibilidade da pesquisa na educação básica, uma vez que a grande maioria dos professores mestres/doutores a realizaram vinculados à rede. Os dados demonstram também que a formação stricto sensu começa a fazer parte da formação continuada do professor da educação básica e, portanto, estimula os programas a pensarem nas últimas diretrizes do PNPG, que prevê a relação entre pós-graduação e docência na educação básica, como apontada anteriormente.

Os números da SEEDF apresentam um percentual de 73,2\% dos professores com mestrado e doutorado de toda a rede pública está em sala de aula. O que contraria a hipótese de que a grande maioria dos professores com essa formação estaria lotada em serviços burocráticos, cargos de chefia, dentre outros. O que faz a diferença? Qual a razão de permanecer na educação básica? Há apoio da SEEDF para optarem por essa permanência? São questões para além deste trabalho, mas que ao longo da discussão procuraremos abordar.

Dentre os 52 sujeitos participantes ${ }^{2}$, 42 são mestres e 10 são doutores. Dos mestres apenas um estava cursando o doutorado. $\mathrm{O}$ doutoramento para professores da educação básica é uma iniciativa muito incipiente ainda, como pode ser percebido pelo número pequeno de docentes vinculados a esse nível de ensino que estão buscando essa formação.

Tendo como referência esse grupo de professores, realizamos a pesquisa empírica em 2011 e 2012, utilizando questionários - 76 entregues e 52 devolvidos - e entrevistas com sete (7) professores com formação stricto sensu da rede pública de Educação do Distrito Federal. A análise do material nos permitiu a construção dos seguintes eixos temáticos: I) o perfil; II) a trajetória profissional, com enfoque no ingresso na educação básica e no curso de pósgraduação stricto sensu (mestrado e doutorado); III) perspectivas e desafios da formação stricto sensu. Essa opção se deve à importância de tal trajetória para a constituição do trabalho docente.

\footnotetext{
${ }^{1}$ O Plano de Carreira do Magistério Público do Distrito Federal (Lei N. 4.075) não prevê mudança de cargo com a titulação de mestre ou doutor, acrescenta a cada título $25 \%$ de adicional de titularidade, em termos financeiros.

2 A definição dos participantes da pesquisa se deu a partir de um amplo período de busca pelas escolas que apresentavam em seu quadro mestres e doutores. Ao visitarmos mais de 80 escolas, constatamos que alguns profissionais da educação pertenciam à instituição, porém não estavam na sala de aula, ou muitos já haviam saído da SEEDF ou mudado sua lotação. Dessa forma, automaticamente foram descartados por não se encaixarem no objeto da pesquisa. Apresentamos a proposta de pesquisa a 76 professores, esses aceitaram participar. No entanto, 52 sujeitos foram os que deram a devolutiva com a participação do questionário.
} 
Ao delinear o perfil dos sujeitos da pesquisa, os atributos abordados apontam para um professor com formação stricto sensu que atua na rede pública do DF, com mais de 45 anos, a maioria do sexo feminino, mas com uma boa expressividade masculina e que já viveram um relacionamento estável. Essa caracterização dos professores pesquisados permite perceber algumas especificidades e continuidades da profissão, como a constatação de que primeiro os sujeitos da pesquisa constituem família e depois vão procurar algum programa de pósgraduação. Isso explica o baixo número de solteiros na pesquisa. Além disso, essa caracterização fornece dados gerais que facilitam uma primeira aproximação do universo dos professores e da relação com a formação stricto sensu e o trabalho docente, provocando indagações sobre a perspectiva profissional, as motivações de buscar essa formação, dentre outras.

Na questão da profissionalização, quanto à formação inicial desses professores, como era de se esperar, a formação inicial predomina as licenciaturas devido à exigência legal e o processo de profissionalização que conforme abordamos se dá na formação inicial que é o ingresso na carreira/profissão para o magistério. Grande parte dos professores concentram-se principalmente nas áreas de Pedagogia, Letras e Biologia, com um decréscimo para licenciaturas como Artes, Educação Física. Importante destacar que cerca de $25 \%$ dos participantes ingressaram na SEEDF como professores leigos, somente com a formação Normal médio, e posteriormente graduaram-se.

Mais de $50 \%$ dos professores participantes da pesquisa graduaram-se na UnB e UniCeub, reconhecidas socialmente pelo comprometimento com a formação de professores, embora com perspectivas e projetos de formação diferentes. Ao observarmos a quantidade de instituições públicas e privadas, nota-se que foram citadas nove (9) instituições privadas, totalizando $60 \%$ das instituições formadoras, e seis (6) instituições públicas com $40 \%$ como instância de formação. Isso demonstra que os sujeitos da pesquisa que buscaram a formação continuada na pós-graduação, em sua maioria vêm da instituição privada, ressaltando-se o seu papel na formação docente. Esse dado se aproxima da realidade apontada por Gatti e Barreto (2009) em sua pesquisa sobre a realidade dos professores do Brasil, a qual destaca que entre as dez maiores universidades do país em número de alunos, apenas três eram públicas, e é sabido que é entre as públicas que estão concentradas as instituições de excelência acadêmica. Porém, é importante destacar que no caso específico do Distrito Federal, a oferta pública é muito baixa, pois conta apenas com uma universidade federal, enquanto a oferta privada passa de 30 instituições, sendo dessas, apenas uma universidade particular. 
A maioria dos professores da SEEDF com formação stricto sensu ingressaram nos programas de formação de mestrado e doutorado nos anos 2000, época que coincide com a criação de um grande número de programas no DF. É importante destacar que a maioria dos professores entrevistados fez o seu curso de mestrado/doutorado recentemente. Poderíamos pensar que esse fato pode indicar que os professores permanecem pouco tempo na educação básica, e abandonam a carreira do magistério nesse nível de ensino, por isso não temos mestres/doutores mais experientes. Porém, alguns relatos trouxeram a justificativa pela permanência nesse nível de ensino, por já terem bastante tempo de serviço e já estarem próximos de se aposentar e que não compensaria abrir mão do magistério na SEEDF. Ao cruzarmos essa suposição com os dados da idade veremos que a hipótese de permanência é bem plausível.

Sobre a motivação para buscar a formação stricto sensu, a partir dos resultados encontrados no questionário, percebemos que as três maiores motivações são: a busca por melhor salário e qualificação; o desenvolvimento de uma investigação científica; e a necessidade de continuar os estudos. Isso demonstra que as motivações estão relacionadas primeiramente às perspectivas profissionais, demonstrando uma aspiração de carreira com melhor condição de trabalho e salário; e à formação continuada, indicando que os professores da educação básica sentem a necessidade de aprofundar os seus conhecimentos e produzir novos na perspectiva da ciência, saindo do senso comum e vislumbrando a pesquisa como possibilidade de formação e transformação da realidade.

Uma contradição encontrada é que a maior motivação sendo traduzida pela busca de melhoria salarial não é confirmada nas entrevistas quando terminada a formação stricto sensu. Ou seja, essas vantagens que antes eram motivações são transformadas em frustrações. Já as motivações que aparecem em menor frequência, como continuar a carreira docente de ensino superior; encontrar solução para um problema vivenciado na escola; construir a unidade teoria e prática da pesquisa; e ingressar na carreira docente de ensino superior. Esses itens estão relacionados à prática profissional, indicando que o professor, mesmo estudando sua prática deseja fazer pesquisa como ciência e não apenas ter uma atitude investigativa diante dela. Outra indicação encontrada se relaciona a negação da educação básica como local de pesquisa e de campo de trabalho para os pós-graduandos, expressando a contradição entre ser mestre e continuar na educação básica.

Em relação às respostas sobre qual o mestrado/doutorado esses professores buscaram, há uma diversidade bastante interessante. A predominância dos estudos está na área de 
Educação, com 30\%. Os programas relacionados às licenciaturas são, sem dúvida, os mais procurados embora haja outros campos de formação. Tal diversidade pode ser de grande valia para a educação básica e deve ser aproveitada pela SEEDF em prol da qualidade da educação, afinal a riqueza da produção de conhecimento em diferentes áreas pode contribuir com esse processo. Mesmo porque há uma multiplicidade de necessidades e objetos relacionados direta ou indiretamente à função social da escola para que seja possível pensar em estratégias e meios para formar e intervir.

A escolha da instituição para realizar o mestrado/doutorado recaiu sobre a instituição pública - a UnB, com adesão de $69 \%$ dos sujeitos pesquisados, revelando a confiança que a universidade pública passa para prestar esse tipo de formação, além disso é a instituição que oferece programa stricto sensu há mais tempo no Distrito Federal, e além desses dois itens, é pública, o que para o professor e para a formação é um ponto de prestígio, conformidade de função social e questão financeira.

Quanto aos principais temas estudados, a pesquisa na área da educação aparece com $50 \%$, devido a maioria ter cursado programa de mestrado/doutorado em educação. Nessa área há um predomínio de assuntos de caráter pedagógico, com a ocorrência de aproximadamente vinte por cento $(20 \%)$ dos trabalhos realizados. O grupo principal, com maior número de trabalho na pesquisa educacional, denomina-se aqui em nossa análise como "o professor e sua prática" - 19,23\%, mostrando a tendência das pesquisas na educação se voltarem para o dia a dia da escola, realizando, a pesquisa não da escola, mas na e com a escola. Foram estudos voltados para o micro, ou seja, para aspectos do cotidiano da realidade escolar e com o objetivo de intervenção.

Outro dado que nos chama atenção é a incidência de estudos relacionados às demais licenciaturas (Biologia, Matemática, Geografia, História) e as outras áreas como Ciência Política, Gestão ambiental, atingindo 50\% dos trabalhos. Nesse caso, o aspecto pedagógico não é prioridade, mas estudos específicos do conhecimento da área, o que nos permite perceber que os estudos se baseiam numa concepção de formação para a pesquisa, baseada em experimentos. Trata-se de um conhecimento produzido que é específico do seu campo de estudo. Há também uma diversidade de temas, assim como na pesquisa na área de educação. Outro fator percebido, pela divisão de números, é que os professores estão interessados na pesquisa e não apenas na pesquisa da prática.

Ao questionar se a pesquisa realizada no mestrado/doutorado está relacionada com sua prática de professor, houve um percentual de $71 \%$ dos professores pesquisados que respondeu 
de forma afirmativa. Os sujeitos relatam que estudaram temas com o qual eles trabalham no exercício da profissão docente. Defendem que pesquisar e produzir conhecimentos na área em que atuam, traz grandes e importantes contribuições para o fazer docente.

Sobre o ingresso na carreira docente, os dados mostram que o exercício profissional tem uma tendência a começar cedo, e que o magistério é a primeira ocupação no mercado de trabalho que ocorre com mais rapidez. É importante lembrar de que há evidências de que o magistério teve a função de estratégia de ascensão social para certas mulheres (HYPOLITO, 1997), o que favoreceu sua procura como possibilidade profissional. Outra razão para escolherem tal profissão é apontada como uma ocupação flexível que permitiria conciliar a vida profissional com outras tarefas do cotidiano.

A maioria dos professores, 35 dos 52 participantes da pesquisa, ou seja, 67,3\%, afirma que ser docente na educação básica foi uma escolha pessoal. Pensar que o ser professor se trata de vocação, vai na contramão do que a categoria dos professores busca em suas lutas ao longo da história: o estatuto profissional e o direito à formação. Entretanto, os professores participantes da pesquisa, por razões culturais e históricas demonstram grande aceitação ao ideário sacerdotal bem como, a perspectiva voluntarista, em que a vontade é a força que move a realidade, desconsiderando a importância das condições concretas, colocam o peso das decisões e das escolhas apenas nos indivíduos e na sua força pessoal.

Alguns dos sujeitos entrevistados atribuem a escolha da profissão docente à identificação com a área de conhecimento, bem como a influência que receberam durante sua formação na educação básica. Relatam que não tinham interesse em estar em sala de aula, mas optaram pela licenciatura para ter oportunidade de emprego.

Observamos também que a profissão docente passa por classificações de status e prestígio de acordo com o nível de ensino em que o profissional atua. A escolha da profissão também recai ao desejo de passar por outras etapas, de ingressar na docência na educação básica para depois poder finalmente chegar à docência universitária ou até mesmo, como no caso da SEEDF, de ser um professor da Escola de Aperfeiçoamento dos Profissionais da Educação (EAPE), educação básica assim, sendo uma espécie de trampolim ou degrau para outro nível de ensino. Destacamos aqui a contradição que existe entre fazer um mestrado e doutorado como forma de resistência, mas também desistência já que é uma forma de deixar de atuar na educação básica. Escolher a profissão de professor e exercê-la, pode ser entendido também como uma forma de resistência, como também destaca Curado Silva (2008) em seu estudo: é uma 
resistência à desqualificação do trabalho docente e como disposição mobilizadora de uma identidade profissional.

Chama atenção o fato de que, mesmo o trabalho docente apresentar condições frequentemente difíceis, se somarmos os que estão satisfeitos com a profissão e os que estão muito, muitíssimo satisfeitos, temos aproximadamente $83 \%$ dos pesquisados; reunindo os que se declararam pouco ou nada satisfeito, temos cerca de $17 \%$.

A satisfação demonstrada pela maioria dos entrevistados não pode ser compreendida como boas condições de trabalho, mas uma forma de resistência contraditória que traz elementos de desistência e acomodação. Como nos aponta Curado Silva (2008), são absorvidas algumas das ideias predominantes sobre o trabalho docente, que levam muitos professores a buscarem saídas individuais que minimizem a dor e a angústia, provocadas pelo constante sentimento de frustração, indicando uma aparente satisfação.

Observamos essa mesma leitura dos dados quando analisamos as aspirações profissionais para um futuro próximo dos professores pesquisados. Ao indicar suas expectativas foram assinaladas diferentes opções, demonstrando a necessidade e a vontade de desenvolver alguma atividade além de ser professor na educação básica.

Boa parte dos professores, 12 sujeitos, querem ingressar na docência do ensino superior, ou seja, pretendem deixar a educação básica. Podemos observar aqui um forte desejo de deixar a docência da educação básica, porém por outro lado, se somarmos aqueles que desejam continuar na educação básica e também serem professores no ensino superior, totalizam 16 sujeitos, representando a maior parcela de sujeitos pesquisados. Outro dado expressivo é a quantidade de professores que anseiam o quanto antes de aposentar (7), já 6 dos pesquisados, influenciados pela formação stricto sensu, pretendem se dedicar à pesquisa, o que para nós também representa deixar o trabalho de sala de aula na educação básica.

Continuar na educação básica com cargo técnico e exercer a docência no ensino superior é o desejo de 4 dos 52 pesquisados. Podemos notar que com a mesma quantidade de professores (4) optaram pela alternativa "outro", citando: continuar professora de ensino básico e paralelamente ingressar em outro concurso na área técnica; trabalhar em clínica particular; atuar na formação continuada de docentes; continuar na formação de formadores; e ingressar na carreira de docência de nível superior como trabalho suplementar e procurar uma carreira com mais reconhecimento profissional fora da docência.

No entanto, o indicativo que temos é que a maioria dos professores mestres/doutores tem intenção de realmente permanecer na educação básica, não excluindo, entretanto, o desejo 
de assim que possível se aposentarem. Essa opção se deve ao fato de muitos já terem o tempo de serviço avançado, não compensando assim, alterar seu campo de trabalho, já que isso acarreta algumas modificações em seus planos de aposentadoria. Esse dado entrecruza com outro já discutido anteriormente, por conta da tardia formação no mestrado e doutorado e precoce ingresso na docência.

Mesmo com todos os problemas que cercam a profissão atualmente, muitos querem permanecer na educação básica, mesmo que seja um nível onde coexistem elementos de acomodação, desistência e resistência no trabalho docente, mostrando que esses profissionais lutam por reconhecimento no seu trabalho. É possível perceber a frequência de professores que querem dedicar-se à pesquisa, o que demonstra a formação de pesquisador proporcionada pelo programa de pós-graduação stricto sensu e, possivelmente, a ideia, o desejo e a possibilidade de pesquisa na educação básica.

Contudo, podemos observar a partir da análise, a necessidade de investimento na educação básica em termos de condições de trabalho, possibilidade de pesquisa e valorização do título. Referente à questão da titulação do professor da educação básica, o plano de carreira da SEEDF, reconhecem a titularidade de especialista, mestre e doutor, prevendo um adicional calculado sobre o vencimento do cargo efetivo do servidor.

Quando o título é apenas um adicional do vencimento, ao invés de uma alteração salarial, há uma economia direta nas demais gratificações. Além disso, o professor se desestimula e é impedido de enfrentar um mestrado/doutorado para adicionar cerca de $8 \%$ no vencimento, o que implica outra economia para o Estado, já que diminui o número de licenças para aprimoramento. Tudo vai contribuindo para que o professor não busque essa formação.

Porém, o que se torna mais grave é pensar que professor de educação básica não precisa cursar um mestrado e/ou doutorado. Essa questão ideológica se torna estratégia política que desgasta e precariza os profissionais da educação desde a sua formação às suas condições de trabalho, estressando sua vida e sua profissão, sob o discurso de "valorização do magistério"; a política é feita para que se realize o necessário e para que o profissional se sinta responsável para resolver no cotidiano os problemas que são estruturais. Mesmo que o adicional traga vantagem de não existir tempo de espera para a mudança de um nível para outro, é visível a não realização da proclamada "valorização do magistério".

Ao falarmos sobre o trabalho docente dos professores da rede pública de educação básica do DF, com formação stricto sensu, revelando suas aspirações, condições de trabalho e atuação profissional, tivemos a intenção de perceber como as questões referentes à 
profissionalização vão constituindo a relação com sua formação no desenvolvimento do trabalho.

A indicação que temos é que os professores estão satisfeitos porque há uma identificação com o trabalho que exercem e consideram de relevância social a função que desenvolvem, porém, ao mesmo tempo encontramos a denúncia da condição de trabalho que está cada vez mais degradante, ao terem que trabalhar três turnos ao dia, em diferentes empregos para complementar seu salário. Podemos enxergar insatisfação também quando relatam suas aspirações profissionais, em que muitos desanimam em dar prosseguimento com um doutorado, pela dificuldade de conciliar trabalho e estudo, por exemplo, ou em ansiar pela aposentadoria, como maior sonho profissional.

Compreender a realidade como um espaço repleto de contradições, como um terreno de lutas, nos mostra que os problemas não se resolvem de uma só maneira. Para pensarmos em soluções precisamos penetrar no terreno denso da concreticidade, buscando entender e captar a síntese das múltiplas determinações que estruturam os processos.

\section{Considerações finais}

Há uma defesa pela investigação da prática docente, porém essa ocorre de forma descontextualizada, apenas prescritiva, propondo que os docentes se transformem em pesquisadores de sua prática. Longe desse propósito consideramos que esse estudo examina a trajetória de formação, da condição de trabalho e carreira necessários para que o professor mestre /doutor de educação básica desenvolva seu trabalho. As práticas escolares assumidas por estes caminham na direção da construção de uma relação mais consciente com o trabalho e as suas finalidades sociais. A pesquisa acaba se tornando um ato de resistência, mas ela não deve ser feita individualmente, é preciso investir em políticas e na profissionalização docente.

As perspectivas e desafios atribuídos à formação stricto sensu apontaram três importantes elementos incidentes ao trabalho docente: a questão da emancipação; autonomia; estranhamento. A pesquisa realizada nesta formação permitiu aos sujeitos desenvolver capacidade de análise e investigação, o que os deixou aptos a formar sujeitos no espírito crítico, na dúvida metódica e na busca da unidade teoria e prática, possibilitando a práxis. Dessa forma, contêm a possibilidade de formar sujeitos autônomos, capazes de dizer não e de tomar as próprias decisões, processos imprescindíveis para o exercício da docência. Contudo, por ainda serem poucos docentes com mestrado e doutorado na educação básica, identificamos um terceiro elemento que incide sobre o trabalho docente, a questão do estranhamento por parte 
dos pares e do próprio professor, o qual às vezes, se torna referência, situação que indica uma ruptura de modelos, levando-o a um não reconhecimento de sua função e local de trabalho.

Foi a partir da voz daquele que lida diariamente com o próprio trabalho, que foi possível aproximar-se das necessidades que permitiram esses sujeitos se movimentarem e buscarem uma formação a partir de algum motivo, que poderia contribuir para transformação ou até mesmo nova significação para sua atividade. Assim, nossa análise não se contentou com a aparência dos fatos, não se propôs fazer simplesmente uma análise das construções narrativas, mas sim do sujeito; fazendo uma análise que nos permitiu apreender a totalidade que representa o sujeito, entendendo-a sempre como aberta, em movimento.

\section{REFERÊNCIAS}

BARREIROS, D. K. Os sentidos e significados da formação stricto sensu no trabalho docente da educação básica. 2013. 135f. Dissertação (Mestrado em Educação) - Faculdade de Educação, UnB, Brasília, 2013.

BRASIL. Ministério da Educação. Coordenação de Aperfeiçoamento de Pessoal de Nível Superior. V Plano Nacional de Pós-graduação. Brasília, DF: CAPES, 2004. Disponível em <http://www.capes.gov.br>. Acesso em: 16 de novembro de 2019.

BECCARI, M. M. B. A pós-graduação e sua atuação no âmbito da educação básica: elementos a partir do caso PPGEDU/UPF'. 2013. 123 f. Dissertação (Mestrado em Educação) - Fundação Universidade de Passo Fundo, Passo Fundo, 2013.

CENTRO DE GESTÃO E ESTUDOS ESTRATÉGICOS. Mestres e doutores 2015: estudos da demografia da base técnico-científica brasileira. Brasília, DF: 2016. Disponível em: https://www.cgee.org.br/documents/10182/734063/Mestres_Doutores_2015_Vs3.pdf. Acesso em: 15 jan. 2019.

CUNHA, L. A. Pós-graduação: no ponto da inflexão? Cadernos de Pesquisa. São Paulo, n. 77, p.63-67, mai. 1991.

CURADO SILVA, K. A. C. P. C. da. Professores com formação stricto sensu e o desenvolvimento da pesquisa na educação básica da rede pública de Goiânia: realidades, entraves e possibilidades. 2008. Tese de doutorado (PPGE - Faculdade de Educação), UFG, Goiânia, 2008.

FERRARO, A. R. A ANPEd, a pós-graduação, a pesquisa e a veiculação da produção intelectual na área da educação. Revista Brasileira de Educação, s/v, n.30, set./out./nov./dez., 2005.

GATTI, B. e BARRETTO Elba S. de S (coords.). Professores do Brasil: impasses e desafios. Brasília: UNESCO, 2009.

HYPOLITO, A. M. Trabalho docente, classe social e relações de gênero. Campinas, SP: Papirus, 1997. 
MARX, K. Contribuição à crítica da economia política. São Paulo: Martins Fontes, 2003.

MARX, K. O capital: extratos por Paul Lafargue. 2. ed. São Paulo: Conrad, 2005.

OBSERVATÓRIO DA EDUCAÇÃO. Observatório do PNE. Acompanhe a situação do plano de educação de cada estado. Disponível em: http://www.observatoriodopne.org.br. Acesso em: 14 nov. 2019.

ROCHA, F. A. M. A formação e a permanência de professores mestres e doutores nas escolas públicas estaduais de São Paulo: o programa Bolsa Mestrado/Doutorado. 2012. 137 f. Tese (Doutorado em Educação) - Pontifícia Universidade Católica de São Paulo, São Paulo, 2012.

SILVA, V. C. da. Impactos da pós-graduação stricto sensu na formação de professores de português da educação básica: do processo de reflexão às transformações no ensino brasileiro. 2015. 85 f. Dissertação (Mestrado em Educação em Ciências Química da vida e saúde) - Universidade Federal do Rio Grande do Sul, Porto Alegre, 2015.

SPAGNOLO, F.; GUNTHER, H. Vinte anos de pós-graduação: o que fazem nossos mestres e doutores? Ciência e Cultura, v.38, n.10, p.1643-1662, 1986.

VELLOSO, J. Mestres e doutores no país: destinos profissionais e políticas de pós-graduação. Cadernos de Pesquisa, v. 34, n.123, p.583-611, set./dez. 2004.

WARDE, M. J. O papel da pesquisa na Pós-graduação em Educação. Cadernos de Pesquisa. n. 73.p.65-75,1990.

\section{SOBRE A AUTORA:}

\section{Dayse Kelly Barreiros de Oliveira}

Doutorado em Educação, pela Universidade de Brasília (UnB); Secretaria de Estado de Educação do Distrito Federal, Brasília, Distrito Federal, Brasil; Programa de Pós-graduação em Educação da Universidade de Brasília; GEPFAPe - Grupo de Estudo e Pesquisa sobre Formação e Atuação dos Professores e Pedagogos. Correio eletrônico: daysekb@gmail.com (iD) http://orcid.org/0000-0002-2686-8698 